\title{
Relationship between Four Tribal Communities and their Natural Resources in the Koraput Region
}

\author{
F. Merlin Franco, D. Narasimhan and William Stanley
}

\section{Research}

\begin{abstract}
In this paper, we look into the relationship that exist between four tribal communities viz. the Kondh, Poraja, Gadaba and Bonda of the Koraput region with their natural resources. Eucalyptus globulus Labill., when introduced into the tribal ecosystem is rejected by the community and so is Acacia auriculiformis A.Cunn ex Benth., while another tree Pterospermum acerifolium Willd. when introduced is readily accepted by the community. A new water reservoir makes fish readily available to the community and the community incorporates the new resource into their culture. The Bonda spare a few tree species from the axe while clearing the forests for shifting cultivation. The possible philosophy behind these actions is discussed.
\end{abstract}

\section{Introduction}

Orissa has the second largest tribal population in India (Choudhuri et al. 1975). As many as 63 tribal communities inhabit the state of Orissa and this diversity provides ample scope for ethnobiological studies (Girach 1992). Botanical Survey of India has done pioneering studies on the tribes of Orissa during 1970-71 (Saxena \& Dutta 1975). Since then, a number of ethnobotanical studies have been carried out on the various tribal communities of Orissa (Aminuddin \& Girach 1991, Choudhuri et al. 1975, Das et al., 1987, Girach 1992, Jain 1971, Mudgal \& Pal 1990, Patnaik 1982, Sahoo \& Mudgal 1995, Saxena \& Dutta 1975, Tribedi et al. 1982). Of the 63 tribal communities inhabiting the state, the Kondh, Poraja, Gadaba and Bonda of the Koraput region, still to a great extent, retain their traditional life style.

The Kondh belong to the Dravidian family and are included under two linguistic groups called Kui and Kuvi (Bailey 1958). The Poraja or Paroja, speak another Dravidian dialect called Parji (Singh 1994). Bell (1945) has reported three subgroups of Gadaba in the Koraput region namely,
The Bodo, San and Ollaro. The Ollaro Gadaba according to him, are a small community who speak Gadaba in the Dravidian form. However, in external appearances, they are similar to the other two subgroups speaking Gadaba in the Mundari form. The Bonda are a tribe of Austro-Asiatic stock spread across 33 villages in the Khairput block of the Malkangiri district and speak a Mundari language called Remo (Patnaik 1989).

This paper is essentially a theoretical discussion that draws upon a few observations made by the first author during a qualitative ethnobotanical study in the Koraput region of Orissa (Figure 1) in India during 2003-2006. It aims at initiating a discussion on the relationship between tribal communities and the natural resources available to them and the implications for biodiversity conservation. The cultural response of tribal communities towards introduction of alien plants, landscape changes that bring in new natural resources to the community and the presence of keystone cultural tree species in shifting cultivated fields are discussed.

\section{Correspondence}

F. Merlin Franco, Department of Botany, Madras Christian College (Autonomous), Chennai 600059, INDIA.

tropicalforezt@yahoo.co.in

D. Narasimhan, Department of Botany, Madras Christian College (Autonomous), Chennai 600059, INDIA.

William Stanley, Integrated Rural Development of Weaker Sections of India/WIDA, Semiliguda, Koraput, Orissa-764036, INDIA.

Ethnobotany Research \& Applications 6:481-485 (2008)

Published: December 30, 2008 


\section{Research Method}

The study was conducted in collaboration with the Integrated Rural Development of Weaker Sections of India (IRDWSI), a Non-profit Organization working with the tribal communities in the Koraput region of Orissa, India. IRDWSI facilitated the study and this enabled us to build a good rapport with the communities studied. Prior to the commencement of the study, community meetings were conducted at every village and the communities were apprised of the purpose of the study, its nature and duration. They were also explained about the two prospective methodologies that could be employed for the study viz., qualitative and quantitative and based on their preference shown for qualitative study, the study was designed to be a qualitative one. Since the languages of the communities involved in the study did not have any script form and as the communities had not received any formal education, oral prior informed consent was obtained from the traditional village councils in lieu of the usual written prior informed consent. The entire study was participatory in nature with the first author living with the communities during the period of work. Open as well as semi-structured interviews were conducted depending upon the need. Plant specimens were identified at the Centre for Floristic Research, Madras Christian College, Chennai with the help of the Flora of the Presidency of Madras (Gamble 1997) and the Flora of Orissa (Saxena \& Brahmam 1994).

\section{Influence of Alien Plants}

Plant and human interrelationships are shaped by history, physical and social environments and inherent qualities of plants themselves (Alcorn 1995). At the same time, different communities view plant sources with varying reverence and use (Senserma 1995). The plants in the forest have 'values' largely because the tribal communities have knowledge about their characteristics and the range of utility (Sahai 2003). For the community to test a plant, experiment and utilise, it has to be an integral part of their ecosystem. Plants that are alien to the tribal ecosystem may seldom be incorporated into their day-today life. The same holds good for plant species that may be of great value to the 'outside' world. This phenomenon is clearly observed in most of the tribal communities living close to the "modern" world. One such example is the relationship between an alien species Eucalyptus globulus Labill., and the Gadaba of Chompakanda of Pottangi block in Koraput district. The tree was introduced into their ecosystem as a part of an afforestation program undertaken by the state forest department. Though E. globulus is a tree of great economic importance that yields pulp for the paper industry and medicinal oil, it is just an alien species for the community and the only use they find for it is to sell it in the local market for firewood. Of late, the Gadaba have started logging off these plants from their forest not for monetary benefits, but to expose the native vegetation growing underneath, on the forest floor. The same is the case

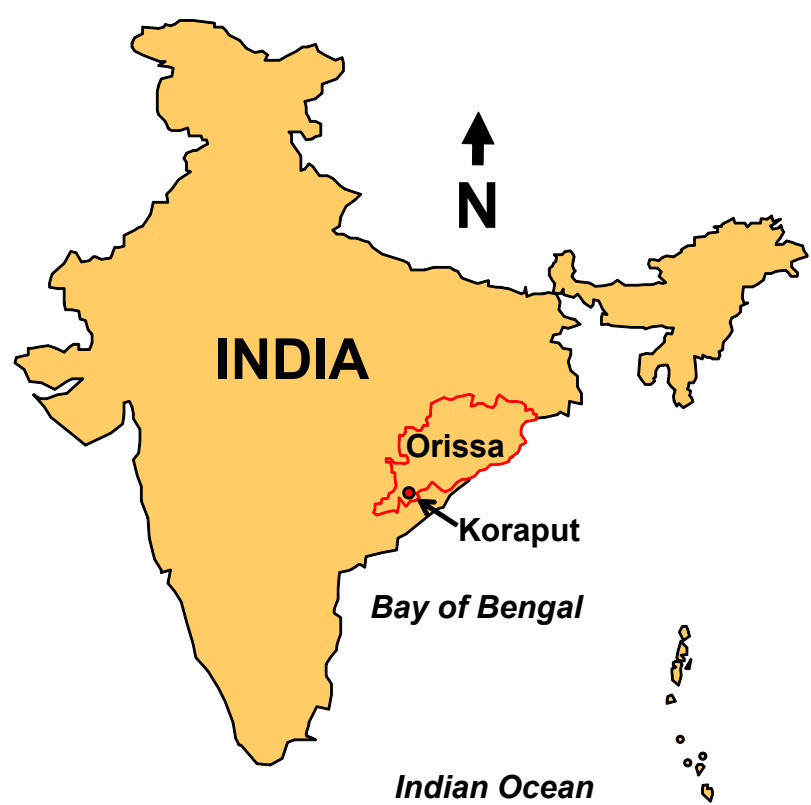

Figure 1. Study area in the Koraput region of Orissa, India.

in Bonduguda, a Kondh village in the Semiliguda block of Koraput district. Their hill slopes were afforested with Acacia auriculiformis A.Cunn ex Benth., an alien species. However, the Kondh find no use for it and describe it as a 'useless tree'. They have started logging off these plants so that their native vegetation could be restored.

The knowledge of the native people in the nonindustrialized regions of the world on their bioresources is extensive (Alcorn 1995). This knowledge enables them to identify any new element in that ecosystem. While alien species are often rejected, there are also cases where such species were accepted into the tribal societies. However, it should be noted that such plants would have enjoyed some kind of indirect relationship with that society. For instance, the Kondh of Kondhpungar in the Semiliguda block of Koraput district use Pterospermum xylocarpum (Gaertn.) Sant. \& Wagh (mochkund) in their ethnomedicine. Its flowers are kept in the ears of women during child delivery to ease pain. But, when another species of Pterospermum, $P$. acerifolium Willd., was introduced from Pakajhola a nearby predominantly Poraja village, the Kondh started using the flowers of this species too. Now, the name mochkund is applied to both the species. $P$. acerifolium owes its acceptance by the tribal society for its similarity with $P$. xylocarpum in appearance as well as in aroma. Moreover, $P$. acerifolium flowers more profusely than $P$. xylocarpum which increases the availability of flowers. Today, both these species enjoy a key status in their ethnomedicine. 


\section{Franco et al. - Relationship between Four Tribal Communities and their Natural Resources in the Koraput Region}

\section{Influence of Landscape Changes}

The tribal way of living is based on their ability to utilize the available natural resources to the maximum to attain selfsufficiency. In their quest to attain self-sufficiency, a newly available natural resource may be used to substitute for an earlier one or a new use may be assigned to an old natural resource. The Poraja of Gullel in the Semiliguda block of Koraput district lost their agricultural fields in the 1980 s to the rising waters of the Kolab dam. The reservoir of the dam which now forms a permanent part of their ecosystem brought plenty of fish. The community started utilizing this new resource and fishing has now been integrated into their culture. The community celebrates an annual ritual hunt, called as choith porv (choith porab) during the spring of every year. In choith porv, the community goes for hunting in the community protected forests. The duration of the hunt generally ranges from seven days to a month. Large scale deforestation and poaching has depreciated the availability of wild animals and hence the hunt nowadays is more of a symbolic representation of the elaborate hunting that happened during the glorious period of the past than a full-fledged hunting festival. The first part of the hunt is usually dedicated towards the hunting of birds and the second part to the hunting of other animals. At end of the festival, a pig or fowl is generally sacrificed. Now, fish too is associated with this ritual whereby the whole village community goes fishing on the final day and prepares a common feast. Fish is also sacrificed to Gangamma, the local deity, a practice that is not found in other Poraja villages. However, it should be noted that fish is least preferred to a pig or fowl and is sacrificed only when it is financially impossible to get a pig or fowl.
The above case shows that culture is open so as to accommodate landscape changes that bring new natural resources to the community. It should also be noted that the community had offered stiff resistance to the setting up of the Kolab dam and Gullel remains as one of the worst affected villages due to the setting up of the dam. The indomitable and enterprising tribal spirit combined with the openness of culture towards landscape changes has helped the community survive the otherwise destructive change brought about in the landscape. Today, freshwater fishing happens to be a major part-time occupation of the Poraja of Gullel.

\section{Keystone Cultural Plants}

Certain plants play a pivotal role in tribal life. Such plants may enjoy a special status in the society. Such plants can be referred to as 'keystone cultural plants'. Hallucinogenic plants that are reported to exert dominant influence upon the cultural beliefs of the tribal societies are a good example of keystone cultural plants. The same status applies to plants that are used to brew or distil liquor. Apart from being used for relaxation and social gatherings, liquor also nourishes them with considerable quantity of calories. Very often, toddy is the only source of food during the summer that happens to be a lean season for agriculture. The Bonda of Malkangiri district are known for their slash and burn type of cultivation. The whole vegetation in an area meant for cultivation is cleared except the jackfruit tree (Artocarpus heterophyllus Lam.), mango tree (Mangifera indica L.) and salop tree (Caryota urens L.) (Figure 2). Jackfruits and mangoes are subjected to fermentation for three consecutive days and then distilled

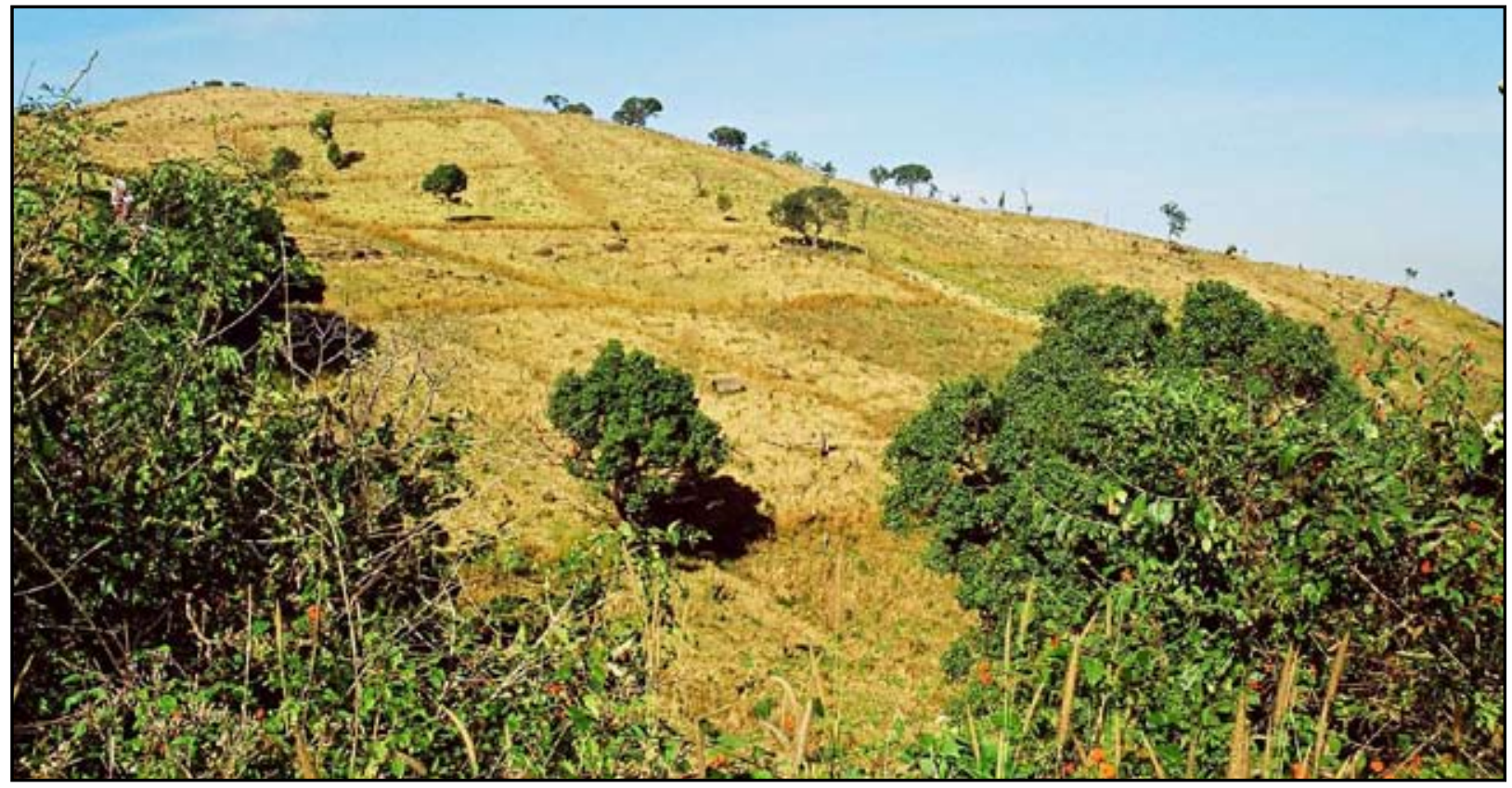

Figure 2. A shifting cultivated field of the Bonda showing trees that were not cut. 
to obtain the much sought-after liquor. The inflorescence of salop tree is tapped to obtain a sap that is brewed and consumed as toddy or distilled to obtain liquor. Liquor and toddy act as the main food during the spring when the annual ritual hunt (choith porv) happens. Both men and women consume them and these liquids fill the air with the needed festival spirit. While on game hunt the men survive on this liquor, toddy and the meagre wild food that are obtained on the way.

While the jack and mango trees grow wild, the salop tree might sometimes be planted even on jungle land. When a salop tree is planted on the jungle land, there is a chance of the land being cleared for shifting cultivation by any individual of the community. Under such circumstances, the salop tree is spared from the axe. However, the tree would now belong to the individual who had originally planted it and not to the individual who had cleared the land, while the land would now belong to the person who had cleared it. The Bonda also employ various rituals to protect the salop tree from evil eyes and diseases which are not required by the jackfruit and mango trees due to their hardy nature. Plants such as Piper trioicum Roxb. and Thunbergia fragrans Roxb. are used extensively in rituals to protect the salop tree. The importance accorded to $A$. heterophyllus, $M$. indica and $C$. urens affirms their position as keystone cultural species of the Bonda community. While the community benefits by obtaining food due to the conservation of such trees, the presence of such trees in a shifting cultivated field helps in checking soil erosion. $A$. heterophyllus and $M$. indica are also considered as ecological keystone species due to their large biomass and higher fecundity rate.

\section{Conclusion}

Top down approaches are fast turning into futile experiments today and conservation involving the local communities has become the norm (Fraser et al. 2005, Hagmann et al. 2002). Understanding the local etiquettes and traditions would augment the conservation efforts. From this study, the basis for a community accepting or rejecting a natural resource can be understood which could help policy makers who advocate introduction of resources into a community's ecosystem to design community friendly conservation projects. A sudden introduction of a completely new species - as was seen with $E$. globulus - might be rejected by the community. There could have been more chances for a Eucalyptus species to be accepted by the community had it been culturally accepted by the community, prior to its physical introduction. Had the community been taken into confidence prior to the physical introduction of the species to help them become familiar with the uses of Eucalyptus, then the chances of the tree to have been culturally accepted could have increased.
This was not required in the case of $P$. acerifolium, as its equivalent $P$. xylocarpum had already been culturally accepted by the community. In the case of the Poraja of Gullel, the change in the landscape was forced upon them by the government and there was a compulsion to respond positively to the change in order to survive. There was no provision available for the community to legally reject or oppose the landscape change. Here too, if fishing was a familiar occupation for the Poraja, the landscape change could have been less painful and there were chances for the Kolab reservoir to be accepted by the community. The Bonda community's practice of sparing a few tree species from being cut while clearing the forests, could be incorporated into projects that aim at limiting the ill effects of shifting cultivation. Such trees could be given priority in afforestation efforts, thus ensuring the community's support for conservation.

\section{Acknowledgements}

We express our sincere gratitude to the Deputy Director and staff of IRDWSI, Semiliguda, Koraput District, Orissa for all the help rendered and Ms. F. Merlin Flower for assisting in the preparation of the manuscript. We also thank all our resource persons, especially, Mr. Hori Hontal of Kondh Pungar, Mr. Poortta Pujari and Mr. Domri Pujari of Bonduguda, Mr. Doni Jani of Putisil, Mrs. Sonai Pangi of Chikalmari, Mr. Sukra Dishari of Chompakanda and Mr. Soma Sisa of Silaiguda, Bondaghat for sharing their valuable knowledge with us.

\section{Literature cited}

Alcorn, J.B.1995. Scope and aims of ethnobotany in a developing world. Pp. 23-39 in Ethnobotany: Evolution of a discipline. Edited by R.E. Schultes \& S. von Reis. Chapman and Hall, London.

Aminuddin \& R.D. Girach. 1991. Ethnobotanical studies on the Bonda tribe of District Koraput (Orissa), India. Ethnobotany 3:15-19.

Bailey, F.G. 1958. Caste and Economic Frontier. Oxford University Press, Bombay.

Bell, R.C.S. 1945. Orissa District Gazetteer (Koraput). Orissa Government Press, Cuttack.

Choudhuri, H.N.R., D.C.Pal \& C.R.Tarafder. 1975. Less known uses of some plants from the tribal areas of Orissa. Bulletin of the Botanical Survey of India 17(1-4):132-136.

Das, P.K. \& M.K. Misra. 1987. Some medicinal plants used by the tribals of Deomali and adjacent areas of Koraput district, Orissa. Indian Journal of Forestry 10(4): 301-303. 


\section{Franco et al. - Relationship between Four Tribal Communities and their Natural Resources in the Koraput Region}

Fraser, E.D.G., A. J. Dougill, W. E. Mabee, M. Reed \& P. McAlpine. 2006. Bottom up and top down: Analysis of participatory processes for sustainability indicator identification as a pathway to community empowerment and sustainable environmental management. Journal of Environmental Management 78(2):114-127.

Gamble, J.S. 1997. Flora of the Presidency of Madras. Bishen Singh Mahendra Pal Singh. Dehra Dun.

Girach, R.D.1992. Medicinal plants used by the Kondh tribe of District Phulbani, (Orissa) in Eastern India. Ethnobotany 4:53-66.

Hagmann, J. R., E. Chuma, K. Murwira, M. Connolly, \& P. Ficarelli. 2002. Success factors in integrated natural resource management R\&D: lessons from practice. Conservation Ecology 5(2):29.

Jain, S.K. 1971. Some magico-religious beliefs about plants among Adibasis of Orissa. Adibasi 12(1-4):39-44.

Mudgal, V. \& D.C. Pal.1990. Medicinal plants used by the tribals of Mayurbhanj (Orissa). Bulletin of the Botanical Survey of India 22(1-4):59-62.

Patnaik, N.1982. Shifting Cultivation in Orissa: Economies of the tribes and transformation. Concept Publishing Co., New Delhi.
Patnaik, N. 1989. The Bondo. Tribal and Harijan Research cum Training Institute, Bhubaneswar.

Sahai, S. 2003. Importance of indigenous knowledge. Indian Journal of Traditional Knowledge 2(1):11-14.

Sahoo, A.K. \& V. Mudgal.1995. Less known ethnobotanical uses of plants of Phulbani District, Orissa, India. Ethnobotany 7:63-67.

Saxena, H.O. \& P.K. Dutta. 1975. Studies on the ethnobotany of Orissa. Bulletin of the Botanical Survey of India 17(1-4):124-131.

Saxena, H.O. \& M. Brahmam. 1994. The Flora of Orissa. Regional Research Laboratory and Orissa Forest Development Corporation Ltd., Bhubaneswar.

Sensarma, P. \& A.K. Ghosh. 1995. Ethnobotany and phytoanthropology. Pp. 69-71 in Ethnobotany: Evolution of a discipline. Edited by R.E. Schultes \& S. von Reis. Chapman and Hall, London.

Singh, K.S. 1994. The Scheduled Tribes. Oxford University Press, Delhi.

Tribedi, G.N., R.N. Kayal \& R.H.N.Choudhuri. 1982. Some medicinal plants of Mayurbhanj (Orissa). Bulletin of the Botanical Survey of India 24(1-4):117-120. 
